\title{
MonitOring\&Remediation
}

\section{Numerical Simulations to Assess the Monitoring Zone Achieved during Low-Flow Purging and Sampling}

\author{
by Mark D. Varljen, Michael J. Barcelona, James Obereiner, and David Kaminski
}

\begin{abstract}
A detailed three-dimensional numerical simulation of ground water flow into the screen of a monitoring well during "low-flow" purging and sampling provides a means to investigate the actual monitoring zone (i.e., "where the water comes from") achieved during these sampling operations. Such a simulation allows for examination of the influence of several variables such as pump placement, well screen and sand-pack configuration, and aquifer heterogeneities on the actual part of the aquifer that is interrogated. In these simulations, ground water was sampled from the entire length of the well screen, although as could be expected, flux was higher into the well screen from zones of higher permeability, if present. Furthermore, at low flow rates, pump position within the screen had little influence on the vertical distribution of flux into the well, and in all cases where a monitoring well partially penetrates an aquifer, the zone monitored extended above and below the well screen. At the low flow rates examined $(250$ and $500 \mathrm{~mL} / \mathrm{min}$ ), there was no increase in flux (from the aquifer into the well screen) adjacent to the pump intake. The major implications of these findings are that a detection monitoring approach predicated on sampling from the entire well screen is valid when purging at low flow rates (i.e., contaminants are not "missed"), or conversely, that discrete vertical sampling may only be accomplished with very short well screens due to potential concentration averaging that would occur along the entire length of a screen. Finally, the simulation results emphasize that aquifer heterogeneities must always be recognized and considered in ground water monitoring design. Aquifer heterogeneities have the most significant influence on the actual monitoring zone (and therefore the potential to "hit" or "miss" contaminants in a detection program). Pump placement and purging rate have little influence on the vertical interval that is sampled (as compared to screen length and placement) and therefore should be selected only so as to minimize sampling artifacts and promote sampling efficiency.
\end{abstract}

\section{Introduction}

The benefits of low-flow purging and sampling in terms of data quality (repeatability, control of false positive results) have been documented in the literature for both volatile organic compounds (Barcelona et al. 1994) and metals (Puls et al. 1992). Furthermore, the operational efficiency and cost-effectiveness have been well established (Schilling 1995; Shanklin et al. 1995). Acceptance and actual implementation of low-flow sampling methods in some situations, however, have been slow or difficult. An often-cited concern is the assumption that a sample collected at a low flow rate only originates from a very narrow vertical interval near the pump intake and that contaminants could be missed. Because of this concern, the issue of where to place a pump in the well screen has become a topic of interest, especially with relatively long-screened wells (i.e., 10 to 20 feet).
In general, these questions result from a limited understanding of the hydraulic performance of wells under lowflow pumping conditions. Elci et al. (2001) performed a detailed simulation of a monitoring well; however, the simulation was only performed under ambient (nonpumping) conditions. The published studies of well performance during pumping have generally focused on concentration changes over time (Reilly and Gibs 1993; Reilly and LeBlanc 1998; Martin-Hayden 2000a, 2000b; Gibs et al. 2000) rather than where the water that is entering the pump intake comes from. Furthermore, published studies on well performance have generally been conducted assuming much higher flow rates than those used for low-flow purging or did not evaluate the specific scenario encountered during low-flow sampling (i.e., the pump located within the screened interval).

For example, Cohen and Rabold (1988) conducted a simulation of hydraulic performance during sampling. The focus of that work was to assess well design. More 
specifically, Cohen and Rabold (1988) investigated whether or not extending a sand pack across the entire thickness of a confined aquifer (fully penetrating sand pack) can allow a short-screened well to collect water from the entire aquifer. While this work did address where the water was coming from, the simulations were conducted at pumping rates ( $1 \mathrm{gpm}$ or $3785 \mathrm{~mL} / \mathrm{min}$ ) up to 15 times higher than rates typical of low-flow sampling ( 250 to $500 \mathrm{~mL} / \mathrm{min}$ ), and in all simulations, the pump intake was located above the screen. The simulations described in this publication examine the effect of pump placement within the screen as well as lower flow rates.

\section{Objectives}

The objective of this work was to assess the vertical interval sampled during low-flow purging and sampling. In addition to showing flowpaths (on a cross section) entering the well screen during low-flow purging and sampling, the work aimed to elucidate the effect of differing well geometry, pump placement, and subsurface heterogeneities on the vertical distribution of flux into the well along the length of the screen.

Specifically, the following are investigated in terms of the vertical flux distribution into the well screen:

- Screen length

- Pumping rate

- Submerged screen vs. screen open across water table

- Pump position in screen

- Formation anisotropy and heterogeneity

- Sand-pack configuration

- Full vs. partial penetration.

This work is not intended to evaluate wellbore processes that may alter chemical concentrations as the water moves from the screen entrance to the pump intake (e.g., mixing within the well) but rather discusses the origin of the water sampled and the vertical distribution of water flowing into a well screen during sampling. Based on observations by Puls and Paul (1998), it appears that mixing processes inside the screen are not a significant factor in terms of sampling results. The data presented by Puls and Paul (1998) demonstrate that for all practical purposes complete mixing occurs even under low-flow pumping (there may be zones inside the wellbore that do not mix; however, these zones do not affect chemical concentrations in a sample). Therefore, the vertical distribution of water flowing into a well screen during sampling is considered to be the most significant factor controlling chemical concentrations in the ground water sample.

\section{Approach}

Simulations were implemented with MODFLOW (McDonald and Harbaugh 1998) using a finite-difference grid spacing of 2 inches. Input of the model structure, population of the finite-difference grid with required parameters, and development of the data files necessary for MODFLOW was completed using the program Processing MODFLOW for Windows ${ }^{\circledR}$ (Chiang and Kinzelbach
2001). Processing MODFLOW fully implements the many features of MODFLOW, including third-party additions to the original MODFLOW code, which includes horizontal flow barriers, preconditioned conjugate gradient solver, etc.

Steady-state flow in the formation near the well, sand pack, and inside of the well during low-flow sampling was simulated.

It should be emphasized that the simulations illustrate steady-state conditions. That is, stabilization of the pumping water level in the well is complete. This is analogous to field-observed stabilization of the pumping water level (and water quality indicator parameters) that must be achieved prior to sample collection under standard low-flow sampling protocols (Puls and Barcelona 1995). Therefore, the results are directly applicable to true field conditions.

Following the steady-state flow simulations, flowpaths were plotted in a cross-sectional view. Flowpaths were computed using PMPATH for Windows (Chiang and Kinzelbach 2001). PMPATH is a particle-tracking program that directly uses the result files from MODFLOW. PMPATH uses the semianalytical particle-tracking scheme described by Pollock (1988) and used by the program MODPATH (Pollock 1989) to calculate the ground water paths and travel times. While the first version of MODPATH is limited to simple forward tracking in steady-state flow fields, PMPATH does forward and backward particle tracking in a steady-state or transient, two- or three-dimensional flow field.

After plotting flowpaths, the cell-by-cell flux terms generated by MODFLOW representing ground water flow into the well screen were tabulated and plotted to obtain a graphic representation of the flux distribution along the length of the screen. Finally, the procedure was repeated with different configurations to illustrate the effects of pumping rate, screen length and configuration, permeability, pump position, differing sand packs, subsurface heterogeneities (horizontal:vertical anisotropy and stratification), and boundary conditions (i.e., fully penetrating vs. partially penetrating screens).

\section{Model Setup}

Figure 1 illustrates the horizontal configuration of the model. The vertical configuration is shown in Figure 2. The domain was 37 rows by 37 columns and was 78 layers (106,782 total cells). The screen zone spanned 30 layers, producing a true three-dimensional simulation, rather than a conventional layered or pseudo three-dimensional simulation where the well screen is modeled as only one layer. If the well was modeled as a single layer, vertical variations of hydraulic flux into the well screen could not have been evaluated. Each cell was two inches square (for a total domain size of $\sim 6$ by 6 feet). The thickness of each layer was uniform in each simulation; however, it varied depending on the screen length specified in each scenario. Layers were 2, 4, or 8 inch thick for 5-, 10-, and 20-foot screen simulations, respectively. Constant head cells were specified along two borders to set up an ambient gradient of $0.002 \mathrm{ft} / \mathrm{ft}$. Before exhaustive model runs were completed, the possible influence of these boundaries was evaluated by completing a baseline simulation and a modified simulation 


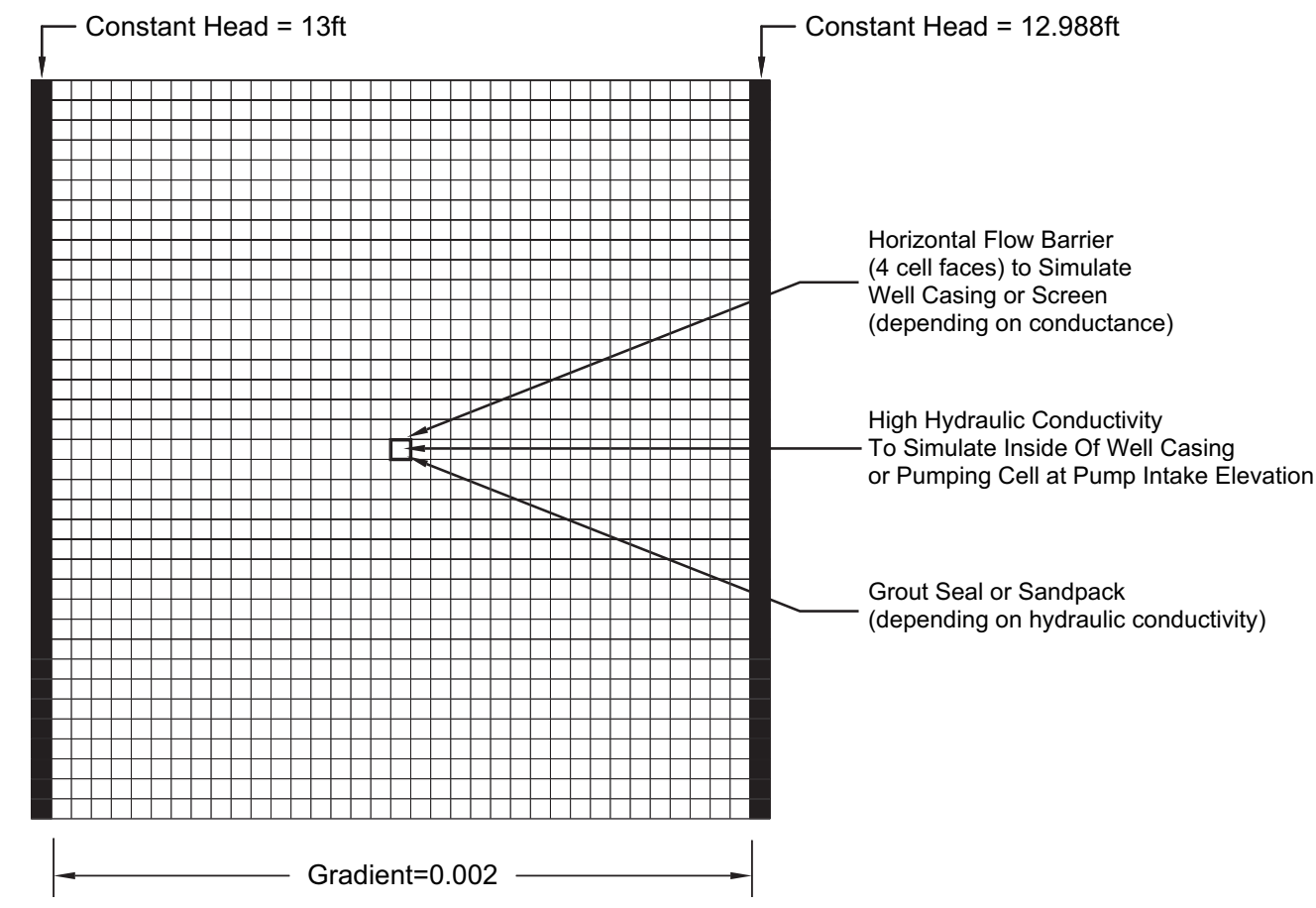

Figure 1. Horizontal layout of model domain.

with an irregularly spaced grid that allowed the constant head cells to be moved farther away from the pumping well. Results of the baseline simulation (hydraulic head contours and configuration of ground water flowpaths) were compared to the modified simulation and no difference was noted. This sensitivity analysis indicated that the boundaries were located sufficiently far enough away from the pumping well to prevent any influence.

The monitoring well was not represented as a single pumping cell, rather a collection of features designed to simulate the complexities of monitoring well design. The only pumping cell designated represented the actual intake of the pump. Horizontal flow barriers were specified as shown in Figure 1 to represent the well casing. Barriers were not used for the well screen, indicating very little resistance to flow, which is considered valid for the gradients and intake velocities achieved during low-flow sampling. A sand pack was represented by a zone of high hydraulic conductivity $\left(10^{-2} \mathrm{~cm} / \mathrm{s}\right)$ immediately surrounding the well screen and extending 1 foot above the well screen. The annular space above the well screen was simulated to be a grout seal by specifying a low $\left(10^{-7} \mathrm{~cm} / \mathrm{s}\right)$ hydraulic conductivity in the "borehole" outside the well casing above the sand pack.

The inside of the wellbore was simulated with a very high hydraulic conductivity $\left(1000 \mathrm{~cm} / \mathrm{s}\right.$ or $10^{6}$ times greater than the formation hydraulic conductivity). While pipe flow and mixing were not explicitly simulated with this approach, a contrast in resistance to flow between the outside of the screen and the inside was represented. Because it was not known exactly what the contrast should have been to represent a real world monitoring well, the sensitivity of the simulations to this assumption was tested. It was determined that the simulations were not sensitive to the hydraulic conductivity value selected for the inside of the well screen, provided the hydraulic conductivity was higher than the surrounding formation (which will always be true). This simplification was therefore of no consequence for the assessment of hydraulic performance under steady-state conditions. However, due to this simplification, the model was not capable of simulating transient mixing. The results of these simulations are therefore only applicable to ground water sampling if sample collection is conducted after hydraulic steady-state conditions have been achieved. As stated earlier, hydraulic steady state is a requirement prior to sampling to ensure water representative of the formation (and not the stagnant water in the blank casing above the well screen) is sampled. In the field, the steady-state condition simulated by the model is indicated by the stabilization of the pumping water level (i.e., when the yield of the well catches up with the pumping rate).

\section{Results}

\section{Baseline Scenario}

The baseline scenario consisted of a monitoring well partially penetrating a homogeneous isotropic formation with a hydraulic conductivity of $10^{-3} \mathrm{~cm} / \mathrm{s}$. The pump intake was positioned in the center of a 10 -foot-long well screen. The pumping rate was $250 \mathrm{~mL} / \mathrm{min}$. To initiate a flowpath analysis, particles were placed at regular vertical intervals along the "upgradient" side of the domain and forward tracked. Figure 3 illustrates the configuration of flowpaths entering the well screen (paths not captured by the well are not shown). Only flowpaths that go into the well are depicted to allow for a convenient illustration of the capture area. All flowpaths above and below those shown 


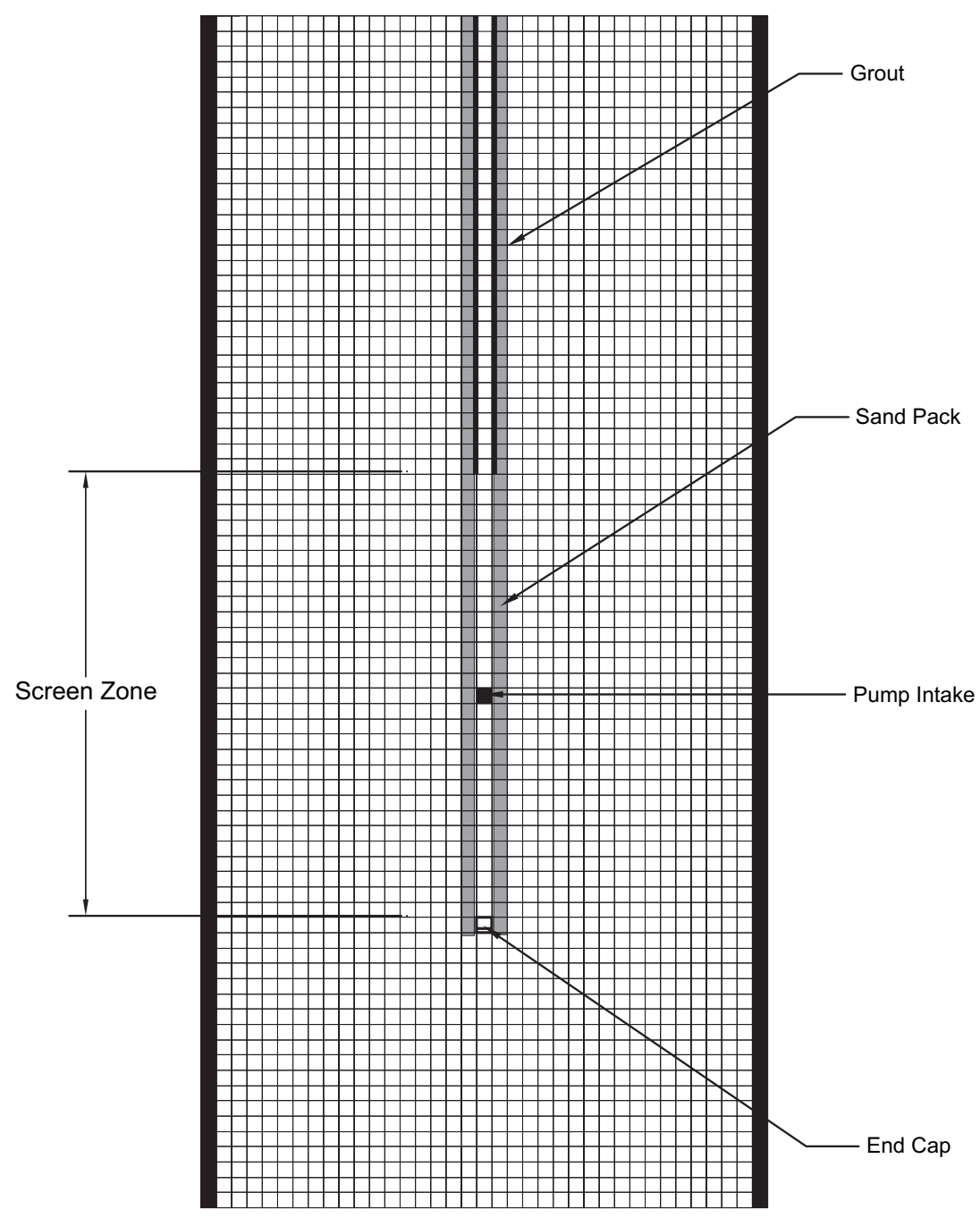

Figure 2. Vertical configuration of model domain.

are not captured and continue on in the ambient flow field. It is noticeable that the actual monitoring zone (the area encompassed by the flowpaths) extended above and below the screen and that the actual monitoring zone extended further above the top of the screen than it extended below the bottom of the screen. This was due to the presence of the sand pack. The sand pack extending above the top of the screen essentially extended the length of the screen.

It should also be noted that the flowpaths originating from above and below the screen bunched up where they entered the screen. This is consistent with the work Cohen and Rabold (1988) conducted at higher pumping rates with the pump intake above the screen. The Cohen and Rabold (1988) simulation included a confining layer below the screen; however, the sand pack extended above the screen, which resulted in "a greater component of upper formation water entering the screen."

Similar to the Cohen and Rabold (1988) simulation, the sand pack acted as an extension of the screen, and the flowpaths "collected" by the sand pack were focused into the top portion of the actual screen. In the baseline scenario, of the 12 particles that were tracked, 5 entered at the top 1-foot interval compared to 1 to 2 entering in the center 1 -foot interval. Four particles entered at the bottom 1-foot interval compared to the one or two that entered at the center 1-foot interval. Where there is no confinement above or below the screen, the vertical dimension of the the actual monitoring zone (as defined by the area inscribed by the flowpaths that are captured by the well) was related to the screen zone length by a factor of approximately two (e.g., for a 10-foot screen, a vertical area of $\sim 20$ feet was captured). Note that this specific finding may only apply to this baseline scenario. Many site-specific factors (heterogeneity, anisotropy, etc.) can affect the specific vertical extent of the area captured.

To further evaluate the movement of water into the screen, cell-by-cell flow terms were tabulated along the length of the well screen. These results are shown in Figure 4 for the baseline case, as well as a simulation conducted at a pumping rate of $500 \mathrm{~mL} / \mathrm{min}$. As a reliability check for each simulation, all the cell-by-cell fluxes into the well screen were summed and compared to the expected withdrawal from the well. In all cases, the summed fluxes were within $10 \%$ of the withdrawal rate. Also, shown in this figure is a graphical representation of the scenario, including pump intake location. The graphical representation of tabulated flux terms is positioned adjacent to the 


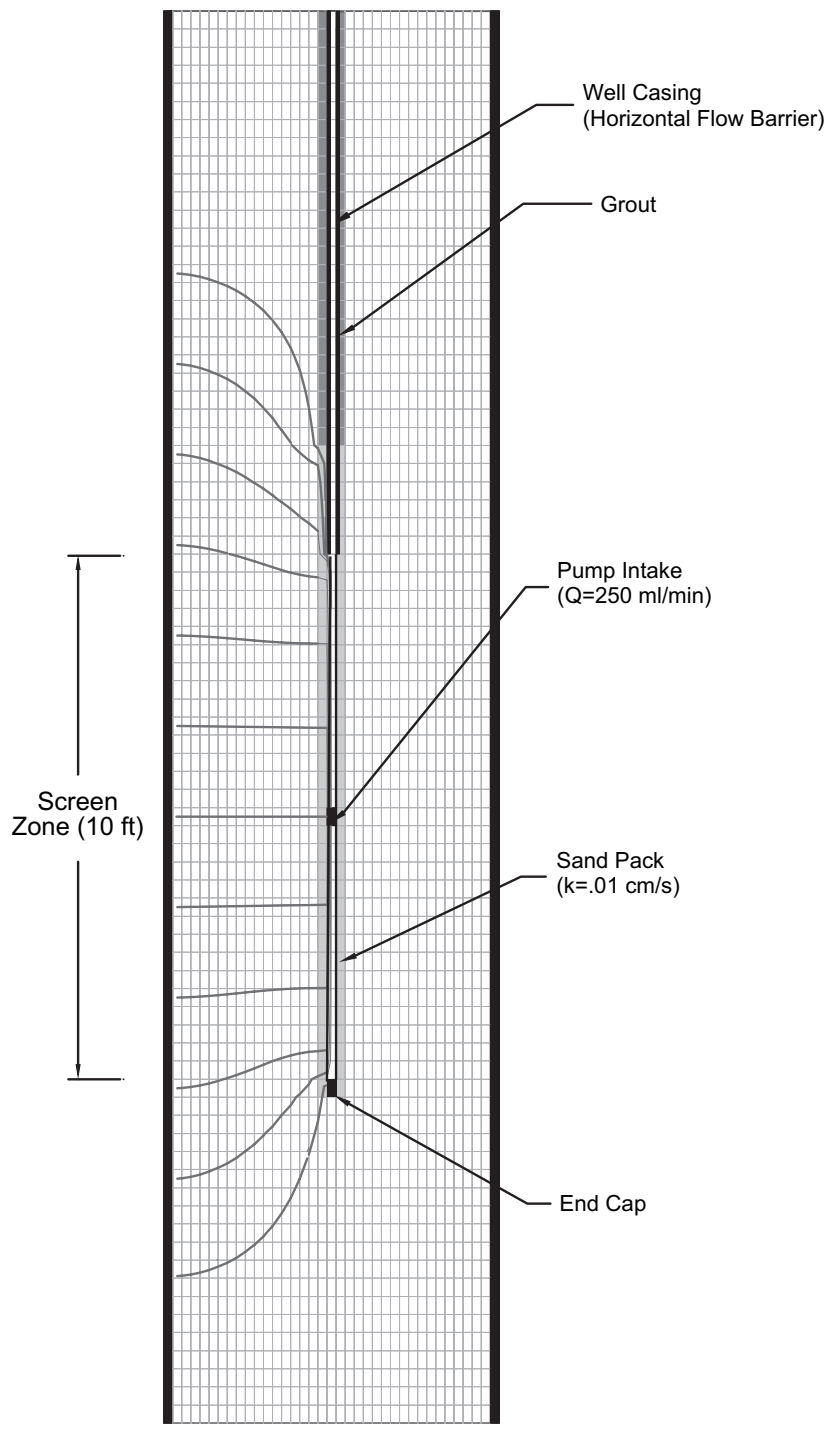

Figure 3. Illustration of flowpaths Under baseline scenario.

screen illustration, so it can be seen where the zones of highest flux relate to the screen.

\section{Screen Length}

Recognizing that in practice many "legacy" well screens are 20 feet in length, the baseline simulation was re-created using a 20 -foot-long screen. Figure 5 shows the

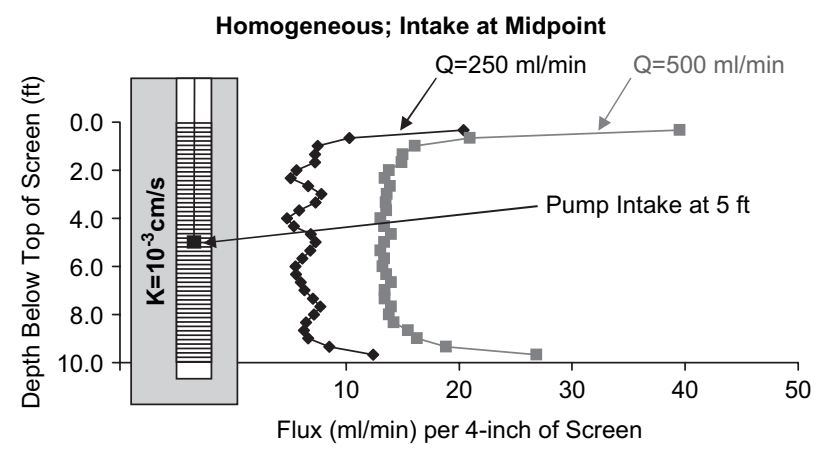

Figure 4. Ten-foot screen.

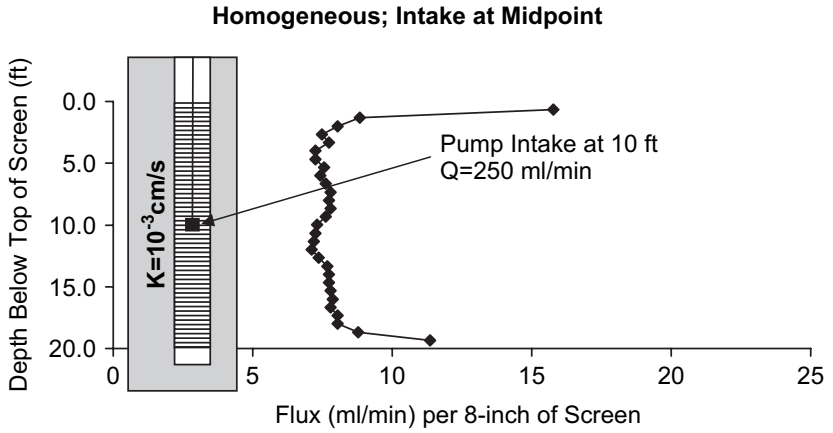

Figure 5. Twenty-foot screen.

flux distribution calculated for the 20 -foot simulation. The vertical flux distribution was essentially the same as that determined for the 10-foot screen.

To allow for a more detailed, higher resolution evaluation of other scenarios, a 5-foot screen was considered. Figure 6 shows the flux distribution for the 5-foot simulation, which was essentially the same as that shown with the baseline 10-foot and 20-foot simulations. Because the flux distributions were similar for the three different screen sizes, it was determined that further simulations would be conducted assuming a 5-foot screen in order to achieve more detailed resolution.

\section{Anisotropy}

The baseline scenario displayed significant vertical ground water movement near the well; therefore, the effect of different horizontal and vertical hydraulic conductivities was explored. A ratio of 10:1 (horizontal:vertical) was specified. All other parameters and assumptions employed for the base case were kept constant. Results are shown in Figure 7. As can be seen in relation to Figure 6, the flux distribution into the well under anisotropic conditions was essentially the same as that simulated in the base case.

\section{Layering}

To illustrate the effect of a monitoring well screen intersecting a layer of higher permeability, the base case was modified to include a thin ( 1 foot) layer of increased hydraulic conductivity positioned 1 foot below the top of the screen. The resulting flux distribution is shown in

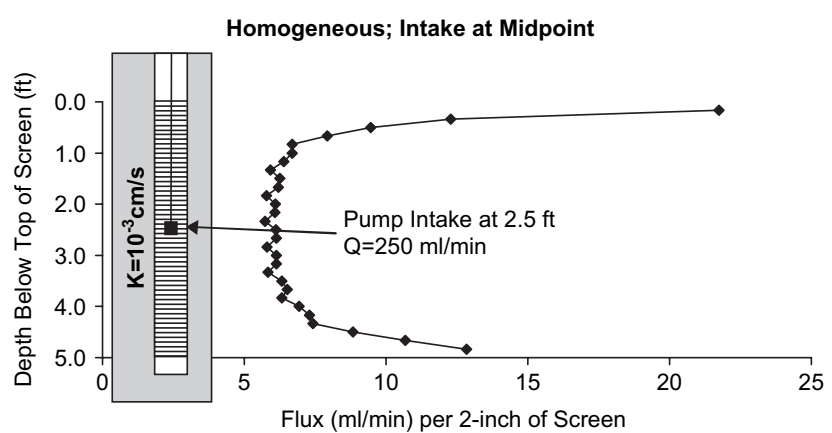

Figure 6. Five-foot screen. 


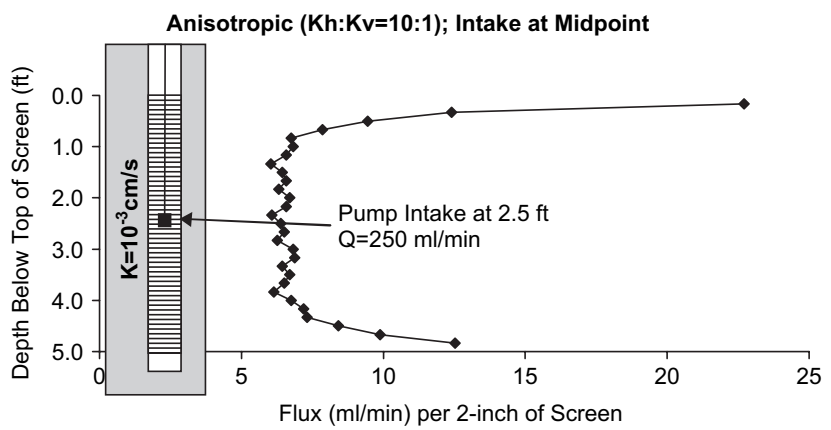

Figure 7. Effect of anisotropy.

Figure 8 . As can be expected, a very large increase in flow into the well occurred adjacent to the high-permeability layer. These results are consistent with those obtained by Cohen and Rabold (1988) at a much higher flow rate and with the pump intake located above the screen.

\section{Pump Intake Location}

The potential benefit of locating the pump intake adjacent to the zone of highest permeability was investigated. Figure 9 shows the results of moving the pump intake adjacent to the zone of high permeability. Compared to Figure 8 (intake in the middle of the screen), no difference was observed in where the water comes from.

The same conclusion may be drawn for position of the pump intake for the homogeneous base case. Figure 10 shows the base case simulation with the intake positioned at the top, bottom, and above the screen. Compared to each other (top, bottom, and above the screen) and compared to the base case simulation with the intake in the middle of the screen (Figure 6), no difference in the location of water entering the well was seen.

\section{Further Investigations of Nonuniform Flux Distribution}

Even though the results showing higher flux per unit screen length at the top and bottom of the screen compared to the center of the screen is consistent with previous work (Cohen and Rabold 1988), further investigation was conducted to help characterize this phenomenon and demonstrate the reasons for this nonuniform distribution. In the baseline simulation, it appeared that the sand pack extending above the screen collected water and directed it into the

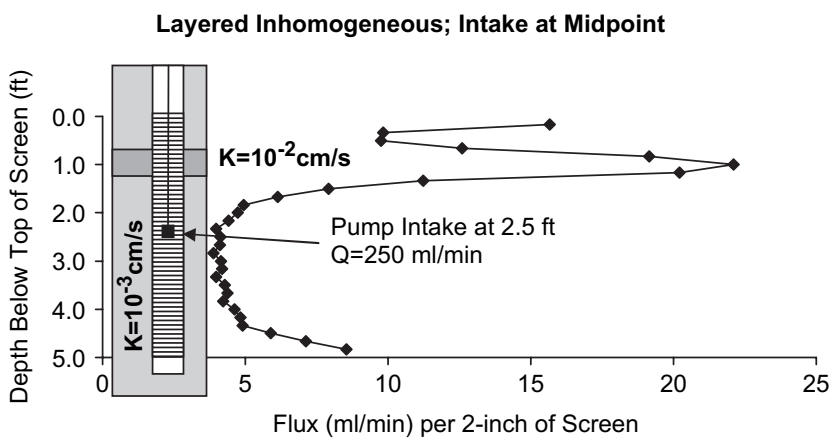

Figure 8. Effect of layering.
Layered Inhomogeneous; Intake at Top

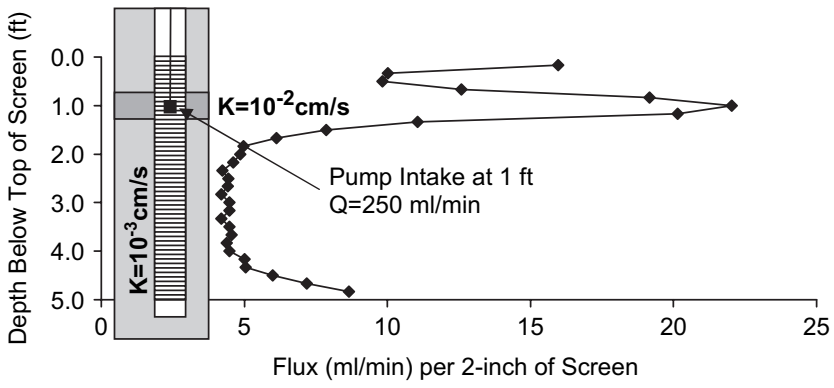

Figure 9. Results of moving the pump intake adjacent to the zone of high permeability.

screen (potentially providing a partial explanation of the higher flux observed at the top of the screen compared to that observed at the center). To investigate this observation, a simulation was conducted without the sand pack extending above the screen (i.e., the grout seal extends all the way to immediately above the screen). As shown in Figure 11, this limited the disproportional amount of flux at the very top of the screen; however, it was not eliminated. Reducing the vertical hydraulic conductivity (anisotropy ration of 10:1) further decreased the disproportionate flux (Figure 12). Sealing the borehole below the screen (Figure 13) similarly reduced the disproportionate flux from below the screen. Finally, a fully penetrating simulation (Figure 14) demonstrated uniform flux along the length of the screen. This group of simulations demonstrated that the disproportionate flux was due to vertical movement of water into the screen from above and below the screen in addition to the horizontal movement, which is all that was observed to enter the middle of the screen.

\section{Wells Completed across the Water Table}

Because many monitoring wells are completed with the screen open across the water table, a final simulation was conducted to illustrate the monitoring zone (configuration of flowpaths) and vertical distribution of flux achieved

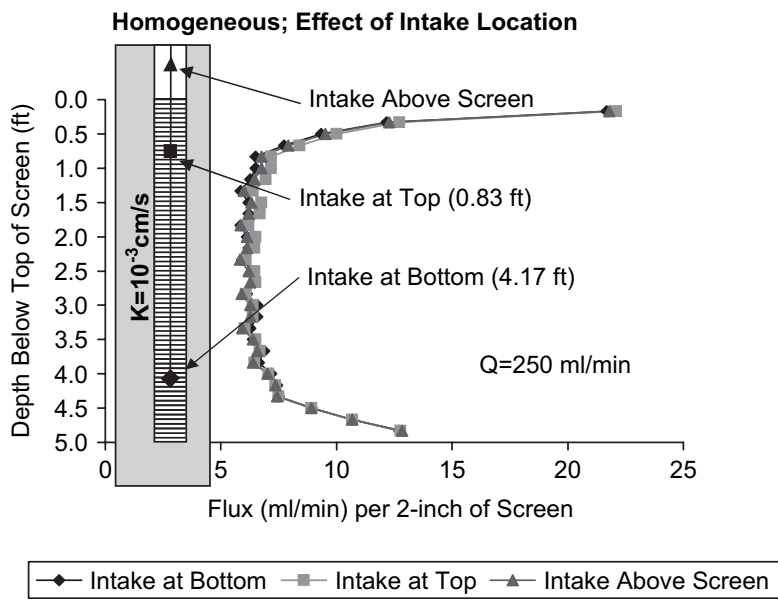

Figure 10. The base case simulation with the intake positioned at the top, bottom and above the screen. 


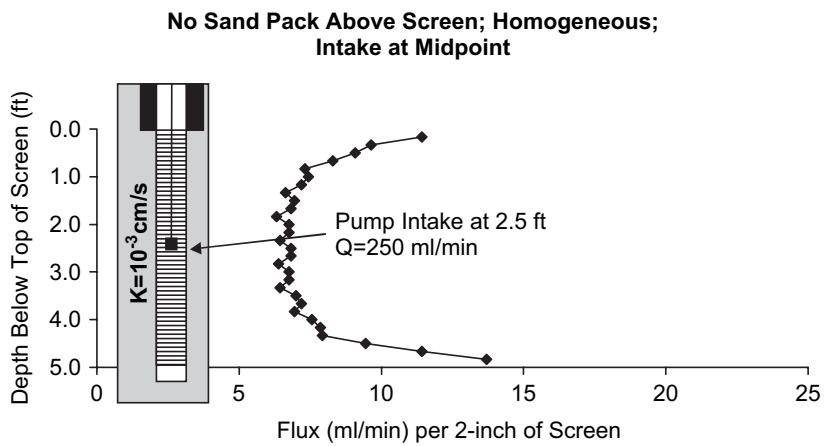

Figure 11. A simulation without the sandpack extending above the screen (i.e., the grout seal extends all the way to immediately above the screen) limited the disproportional amount of flux at the very top of the screen; however, it was not eliminated.

with this type of well configuration during low-flow purging and sampling. All parameters and conditions of the baseline 10-foot screen simulation (Figures 2 and 3) were maintained for this simulation; however, the static water level was set 5 feet below the top of the screen and the pump intake was set in the middle of the water column (7.5 feet below the top of the screen). Figure 15 illustrates the configuration of flowpaths entering the well. Figure 16 shows the distribution of flux along the well screen. Similar to the baseline case, the flux increases at the bottom of the well, likely due to vertical movement of water from below the well in addition to adjacent to the well. There is no increase in flux at the top of the saturated portion of the screen because the water table surface acts as a no-flow boundary (creating a condition similar to the confined or fully penetrating example shown in Figure 16).

\section{Conclusions}

This work illustrates the following points for purging at low flow rates (250 to $500 \mathrm{~mL} / \mathrm{min}$ ) and sampling after steady-state conditions have been achieved (as evidenced by stabilization of the pumping water level and water quality indicator parameters):

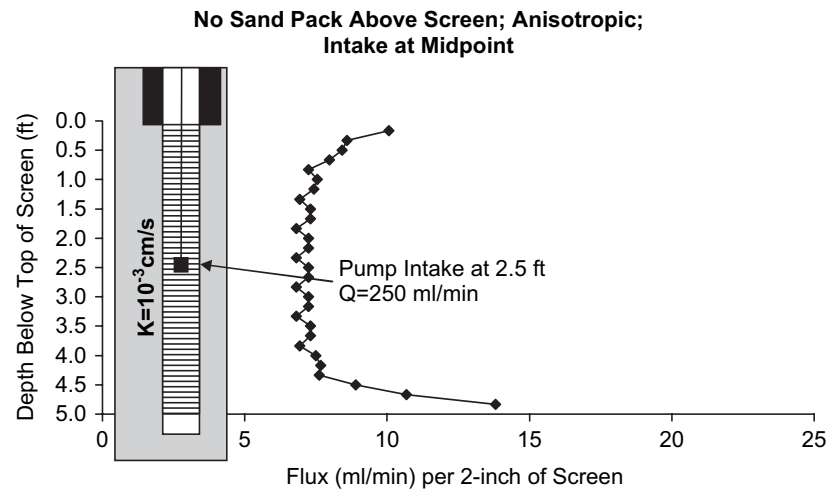

Figure 12. Reducing the vertical hydraulic conductivity (anisotropy ration of 10:1) further decreased the disproportionate flux.

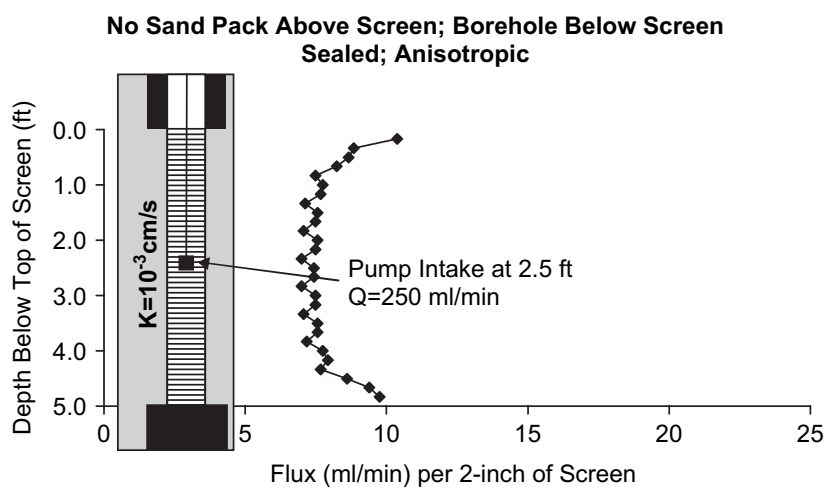

Figure 13. Sealing the borehole below the screen reduced the disproportionate flux from below the screen.

- The entire well screen is sampled, although preferential flux into the screen occurs if the screen intersects a zone of higher permeability. This result was consistent for screens that were 5,10 , and 20 feet in length.

- The location of the pump intake within the screen does not influence the actual zone sampled.

- If the monitoring well partially penetrates an aquifer, some flowpaths that enter the well screen originate from above and below the screen, so the actual zone monitored is longer than the length of the screen (provided there are no overriding vertical heterogeneities in permeability).

The finding that wellbore flow would occur (resulting in the entire screen zone being sampled) in response to low volume/rate pumping is consistent with the work of Reilly et al. (1989) and Hutchins and Acree (2000) who found that significant intrawellbore flow can occur in response to very small head changes under ambient conditions. This finding is also consistent with the empirical findings of Puls and Paul (1998). Puls and Paul (1998) demonstrated in a field experiment that a sample collected using low-low purging was reflective of the average of discrete direct-push samples collected adjacent to and along the entire length of the screen. Because the discrete samples showed considerable vertical variation, this supports the notion that the entire well screen is sampled during

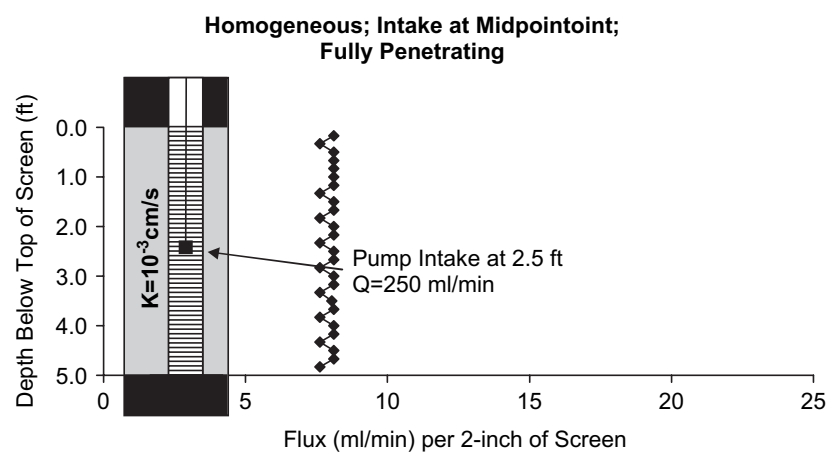

Figure 14. A fully penetrating simulation demonstrated uniform flux along the length of the screen. 


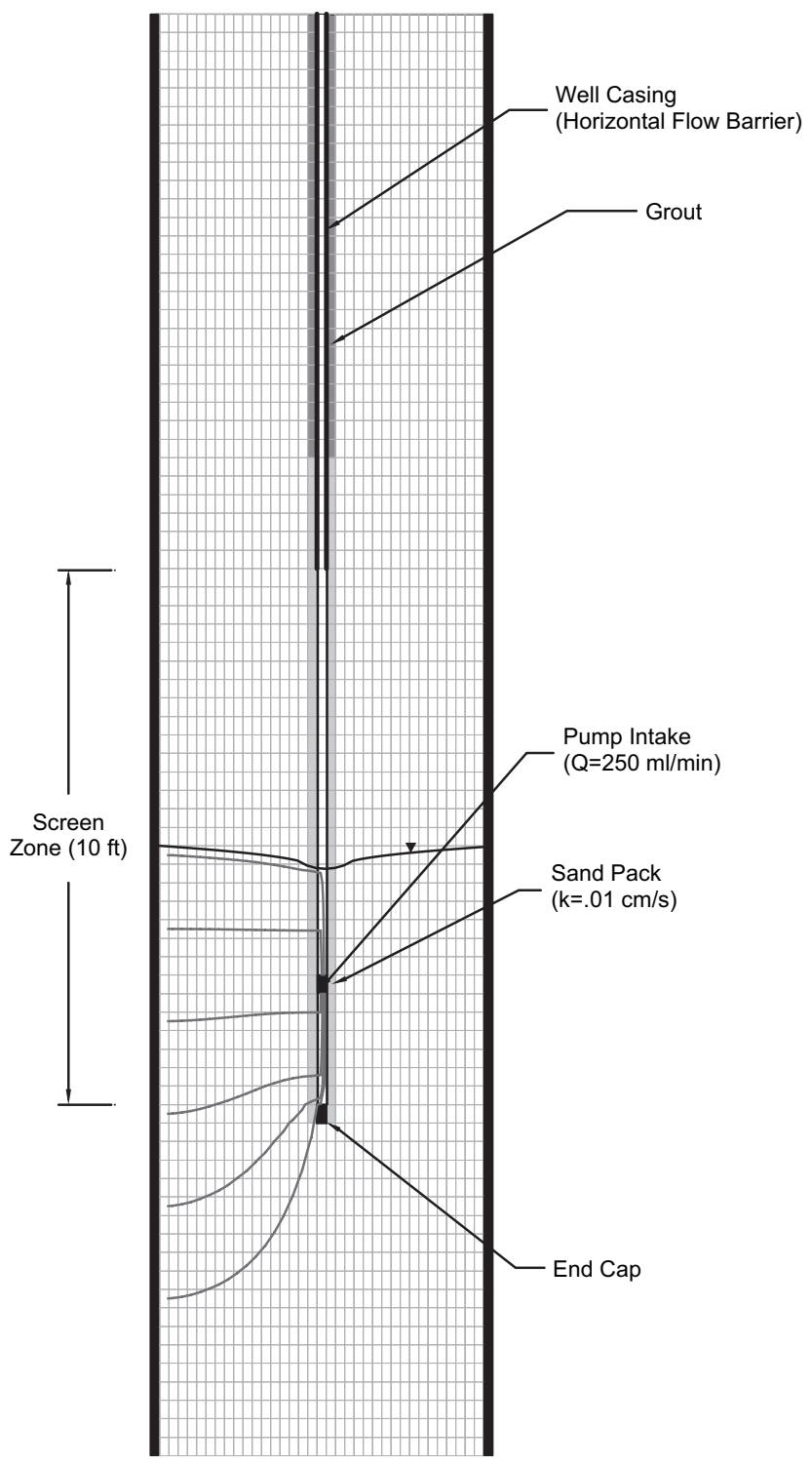

Figure 15. Illustration of flowpaths when screen intersects water table.

low-flow sampling and that mixing inside the well screen is essentially thorough for all practical purposes.

This quantitative illustration showed preferential flux into the screen if the screen intersects a zone of higher permeability (this increased flux would occur regardless of

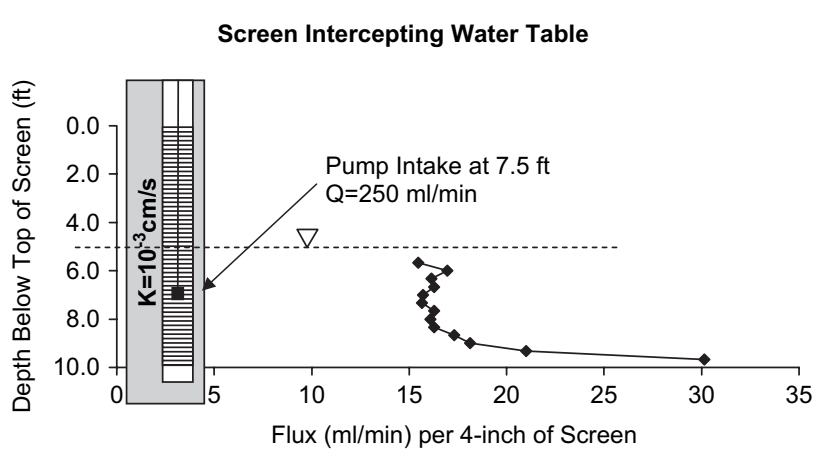

Figure 16. Screen intercepting water table. the flow rate). This finding supports previous qualitative recommendations to specify screen lengths and positions according to known heterogeneities (Keely and Boateng 1987; Gibs et al. 1993; Barcelona et al. 1994; Puls and Barcelona 1995; Martin-Hayden and Robbins 1997).

Changing pump position within a screen, however, does not provide an opportunity to collect discrete samples. Recommendations for pump intake location are simply to keep it within the well screen instead of above it to minimize mixing with "stagnant" water and the required purge volume and to keep the intake off the bottom of the well where accumulated sediment may be drawn into the sample. It was demonstrated that it is not necessary to locate the pump intake above the well screen to obtain water from the entire screen. Locating the intake above the screen means more stagnant water must be purged (reducing the efficiency of the sampling operation), and because wellbore mixing processes are not perfectly understood, the possibility of obtaining representative samples (i.e., not mixed with the stagnant water) may be more difficult to ensure. Locating the pump intake at any location within the well screen provides the best opportunity to collect samples representative of water across the entire well screen, and because the entire well screen is sampled, the shorter the well screen, the less concentration averaging (across different vertical intervals) can be expected to occur.

\section{Acknowledgments}

The authors wish to acknowledge the support of Waste Management Inc., as well thank Paulo Negrao, Clean Environment-Brazil, for assistance with the graphics.

Editor's Note: The use of brand names in peer-reviewed papers is for identification purposes only and does not constitute endorsement by the authors, their employers, or the Ground Water Association.

\section{References}

Barcelona, M.J., H.A. Wehrmann, and M.D. Varljen. 1994 Reproducible well purging procedures and VOC stabilization criteria for ground water sampling. Ground Water 32, no. 1: 12-22.

Chiang, W.-H., and W. Kinzelbach. 2001. 3D-groundwater modeling with PMWIN: A simulation system for modeling groundwater flow and pollution. Berlin, New York: Springer.

Cohen, R.M., and R.R. Rabold. 1988. Simulation of sampling and hydraulic tests to assess a hybrid monitoring well design. Ground Water Monitoring Review 3, no. 1: 51-59.

Elci, A., F.J. Molz III, and W.R. Waldrop. 2001. Implications of observed and simulated ambient flow in monitoring wells. Ground Water 39, no. 6: 853-862.

Gibs, J., G.A. Brown, K.S. Turner, C.L. MacLeod, J.C. Jelinski, and S.A. Koehnlein. 1993. Effects of small-scale vertical variations in well-screen inflow rates and concentrations of organic compounds on the collection of representative ground water quality samples. Ground Water 31, no. 2: 201-208.

Gibs, J., Z. Szabo, T. Ivahnenko, and F.D. Wilde. 2000. Change in field turbidity and trace element concentrations during well purging. Ground Water 38, no. 4: 577-588. 
Hutchins, S.R., and S.D. Acree. 2000. Ground water sampling bias observed in shallow, conventional wells. Ground Water Monitoring and Remediation 20, no. 1: 86-93.

Keely, J.F., and K. Boateng. 1987. Monitoring well installation, purging, and sampling techniques-Part 1: Conceptualizations. Ground Water 25, no. 3: 300-313.

Martin-Hayden, J. 2000a. Sample concentration response to laminar wellbore flow: Implications for groundwater data variability. Ground Water 38, no. 1: 12-19.

Martin-Hayden, J. 2000b. Controlled laboratory investigations of wellbore concentration response to pumping. Ground Water 38, no. 1: 121-128.

Martin-Hayden, J., and G.A. Robbins. 1997. Plume distortion and apparent attenuation due to concentration averaging in monitoring wells. Ground Water 35, no. 2: 339-346.

McDonald, M.G., and A.W. Harbaugh. 1998. A modular threedimensional finite-difference ground water flow model. USGS Open-File Report 83-875. U.S. Geological Survey, Denver, Colorado.

Pollock, D.W. 1989. MODPATH, documentation of computer codes to compute and display pathlines using results from the U.S. Geological Survey modular three-dimensional finite-difference groundwater model. U.S. Geological Survey Open-File Report 89-381. U.S. Geological Survey, Reston, VA.

Pollock, D.W. 1988. Semianalytical computation of path lines for finite difference models. Ground Water 26, no. 6: 743-750.
Puls, R.W., and M.J. Barcelona. 1995. Low-flow groundwater sampling procedures. Ada, Oklahoma: National Risk Management Laboratory, U.S. EPA.

Puls, R.W., D.A. Clark, B. Bledsoe, R.M. Powell, and C.J. Paul. 1992. Metals in ground water: Sampling artifacts and reproducibility. Hazardous Waste and Hazardous Materials 9, no. 2: 149-162.

Puls, R.W., and C.J. Paul. 1998. Discrete-level ground-water monitoring system for containment and remedial performance assessment objectives. Journal of Environmental Engineering 124, no. 6: 549-553.

Reilly, T.E., O.L. Franke, and G.D. Bennett. 1989. Bias in groundwater samples caused by wellbore flow. Journal of Hydraulic Engineering 115, no. 2: 270-276.

Reilly, T.E., and J. Gibs. 1993. Effects of physical and chemical heterogeneity on water quality samples obtained from wells. Ground Water 31, no. 5: 805-813.

Reilly, T.E., and D.R. LeBlanc. 1998. Experimental evaluation of factors affecting temporal variability of water samples obtained from long-screened wells. Ground Water 36, no. 4: 566-576.

Schilling, K. 1995. Low-flow purging reduces management of contaminated groundwater. Environmental Protection 6, no. 12: 24-26.

Shanklin, D.E., W.C. Sidle, and M.E. Ferguson. 1995. Micropurge low-flow sampling of uranium contaminated ground water at the Fernald Environmental Management Project. Ground Water Monitoring and Remediation 15, no. 3: 168-176. 